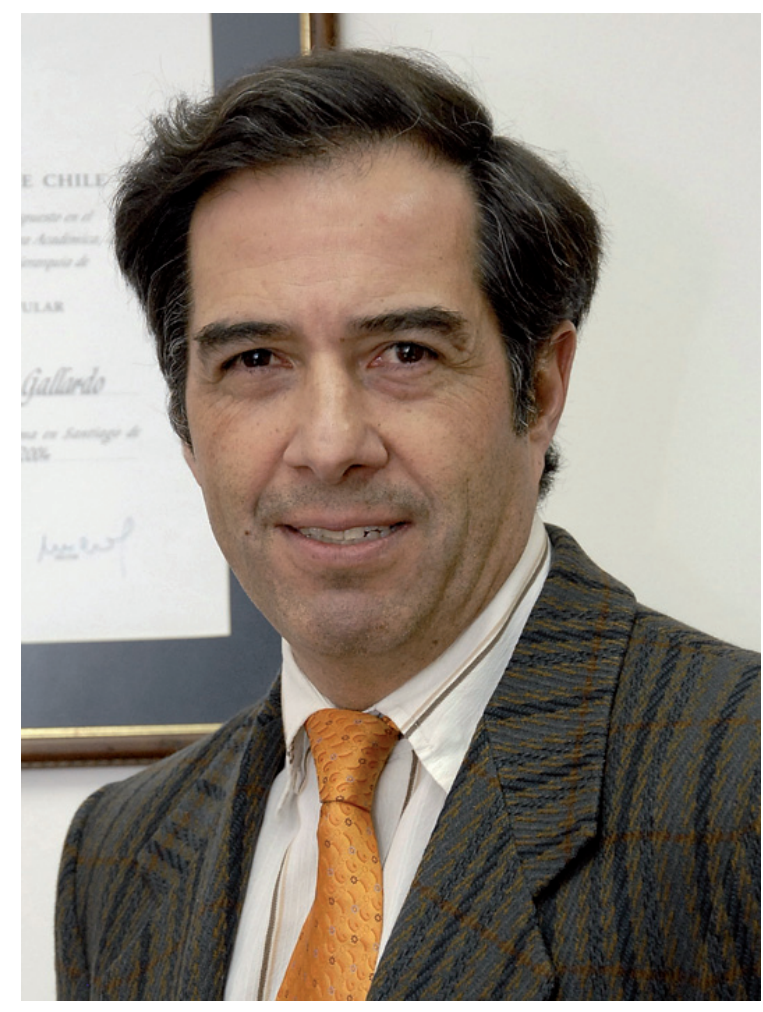

Vivencias en torno al círculo virtuoso Educación, Medicina, Ciencia, Universidad: Hitos y proyecciones para un país que aspira al desarrollo

"Mi vida es una vida hecha de todas las vidas: las vidas del poeta" expresaba Pablo Neruda en su célebre libro de prosa "Confieso que he vivido". Guardando las debidas proporciones, en estos veloces 52 años de vida y 28 años de profesión, siento que he vivido, y de alguna manera son estas vivencias relacionadas, fundamentalmente, con lo profesional y académico (invariablemente cubierto por el manto de lo afectivo que intentaré no profundizar hoy), que desarrollaré con ustedes, familiares, amigos, profesores, colegas médicos, académicos, e investigadores. Hago mía e interpreto la primera frase de Pablo: mis propias vivencias, logros, y reflexiones son un producto colectivo de todas las maravillosas vidas con que he interactuado y que han ido formando mi pensar y mí sentir. En atención al Propósito Fundamental de esta Academia de Medicina "contribuir al progreso del conocimiento médico en todos sus aspectos, que aspira a ser la conciencia reflexiva de la medicina chilena", y a su misión de "dedicarse al estudio de los problemas de la práctica médica, la educación y la salud pública y proponer soluciones para los mismos", me concentraré en las vivencias que relaciono con los cuatro temas destacados en el título, Educación, Medicina,

\section{Miguel O'Ryan Gallardo nuevo miembro en la Academia de Medicina de Chile}

\author{
Miguel O'Ryan Gallardo, a new member \\ of the Academy of Medicine of Chile
}

\begin{abstract}
Reproducimos su discurso de incorporación a tan excelso estamento. El Editor
\end{abstract}

Ciencia y Universidad, temas que cual más, cual menos, tocan a buena parte de ustedes y, en los cuales he tenido la fortuna de recibir tanto de tantas personas.

Intentaré un transcurso cronológico aunque me permitiré comenzar por el final, con mi profundo agradecimiento a los destacados colegas de la Academia que me honraron con esta designación. Me honra el sillón 17, sillón que fuera ocupado desde el año 1972 hasta el año 2009, por mi predecesor, el destacado médico fisiólogo y fisiopatólogo Dr. Bruno Günther Schaffeld. No conocí personalmente al Dr. Günther, quien fuera para mí, como para muchos, un hito humano en la historia de la Medicina chilena. Me permito hacerle un sentido homenaje a él y a su legado, repitiendo las siguientes palabras pronunciadas por el Dr. Alejandro Goic al momento de despedir al Dr. Günther "profesor universitario por antonomasia, un notable investigador cientifico y una persona de gran inteligencia, de firmes convicciones, amable y acogedor, y dotado de un agudo sentido del humor". Con toda humildad, y guardando por segunda vez las debidas proporciones, me identifico plenamente con la aspiración a poseer alguna de estas cualidades, destacando en el aspecto formativo, la activa promoción que el Profesor Günther desarrolló por la integración de la investigación básica con la medicina clínica, promoviendo con fuerza la formación científica de generaciones de profesionales de la salud en Chile. Este concepto impulsado por el Dr. Günther y muchos otros colegas en esta Academia, constituye a mi parecer uno de los pilares del círculo virtuoso de la formación del médico para Chile: Médicos con una sólida formación científica, capaces de sustentar una práctica médica efectiva en una sólida capacidad de análisis basado en la evidencia, la reflexión serena, visión crítica y autocrítica. En un país donde el significativo desarrollo material de las personas durante las últimas décadas ha tendido a disociarse en no pocos momentos del desarrollo intelectual, disociación que abarca también el ambiente 
profesional incluyendo el mundo de la salud, este concepto cobra relevancia significativa y permanente.

Una rápida reflexión relacionada a este concepto: pienso que acortar las carreras de la Salud, tema de candente y entusiasmante debate hoy, es posible en la medida que los currículos se concentren en formar a profesionales para que adquieran estas capacidades, y no en contenidos específicos, cada vez crecientes. Por el contrario, creo que acortar carreras profesionales en desmedro de una sólida formación del pensar, para beneficiar la adquisición de "competencias técnicas" sería un serio retroceso para un país que aspira a niveles más altos de desarrollo, al menos para aquellas carreras que, decidamos en conjunto, deben ser de formación profesional.

Me permito retrotraerlos ahora a, aproximadamente, cuarenta años atrás, hacia el convulsionado período de los años 70, período durante el cual desarrollé mi educación secundaria. Ingresé en octavo año de enseñanza básica al Liceo 11 de Las Condes, como un joven proveniente de una familia de padres profesionales, comprometidos con su país, acomodada económicamente, aunque austera, en un hogar en que recibí mucho afecto, valores "republicanos", el sentido de lo público, de la sencillez, el trabajo bien hecho, la tolerancia, e innumerables oportunidades, incluyendo una niñez privilegiada en Estados Unidos de América. Amerita la solemnidad de esta ceremonia el agradecer a mis amados padres y hermanos, quienes han sido parte fundamental de mi vida y de lo que soy. En lo más estrictamente práctico, debo destacar la relevancia que ha tenido en mi desarrollo profesional la "gracia" de haber podido aprender el inglés como primer idioma. Esta oportunidad me ha abierto innumerables puertas y me ha permitido ayudar a abrirles puertas a otros colegas y amigos. El aprendizaje precoz de inglés u otro idioma debe ser una aspiración decidida de el país que pretende darles oportunidades a sus jóvenes. Vuelvo al Liceo 11 de Las Condes, donde permanecí cinco años, porque de él quisiera resaltar vivencias que considero fundamentales. Recuerdo, vagamente, las salas precarias, vidrios rotos, baños deteriorados, y recuerdo con fuerza presente la solidaridad de mis compañeros, respetuosos en la diversidad, el esfuerzo, la complicidad, la amistad; en su gran mayoría provenientes de familias de la esforzada clase profesional o técnica que le ha dado tanta dignidad y prestancia a este remoto y pequeño país. Agradezco de corazón la presencia de varios de ustedes, Pato, Beltrán, Jaime, Pablo, Samuel, hoy día en esta ceremonia. Con la misma fuerza siento que fuimos bendecidos por una educación pública de calidad basada, fundamentalmente, y aquí destaco sin vacilación, en profesores con vocación y nivel de preparación, que mirado con la perspectiva del tiempo, puedo decir fueron verdaderos "maestros" que modelaron nuestras mentes y también en buena parte nuestros corazones. El Profesor de Biología Jorge Avilés, educador por antonomasia, es un digno ejemplo de los "maestros" de la educación chilena. No me cabe duda que la esencia de la formación de calidad del joven chileno está en tener el máximo número posible de "maestros", igracias Jorge por estar aquí! Toda estrategia y política para lograr la generación, sustentación y reconocimiento de "maestros" en todos los rincones de Chile debe ser bien recibida y ferozmente impulsada.

Ingresé a estudiar Medicina a la Pontificia Universidad Católica en un ambiente nacional de represión y temor, no pocas veces soslayado, consciente o inconscientemente en el ambiente que me tocó estudiar. Durante diez años, hasta terminar egresado como médico pediatra, aprendí quizás de una manera imperceptible una cierta rigurosidad y metódica para el estudio y el enfrentamiento de problemas, por cierto gracias a muchos profesores-investigadores rigurosos, perseverantes y dedicados a sus alumnos, varios son miembros de esta distinguida academia. Nació en estos años con fuerza mi vocación de investigador y la necesidad de ampliar mi horizonte más allá de las murallas de la universidad en que crecí, donde se enseñaba la medicina con fervor, aunque a veces en mi percepción, de una forma algo más endogámica de lo deseable. En estos años de universidad, en esa conjugación a veces imperceptible de planificación y situaciones fortuitas (lo que algunos llaman "destino") conocí a mi querido compañero y amigo Humberto Soriano, y a través de él, permitiéndome una leve disgregación de lo académico y profesional, a uno de los tesoros más relevantes de mi existencia, una mujer amorosa, abnegada, compañera dispuesta a todo para aceptar a un potencial futuro médico que terminó siendo un "investigador". Agradezco a Inés en este momento, públicamente, por TODO lo que me ha dado en estos treinta y seis años de vida en común. Pero, además, tuve la fortuna de conocer e interactuar con el Dr. Humberto Soriano Pérez, hoy mi suegro y amigo, quien me introdujo en la investigación clínica, y quien me dio las primeras armas para desarrollarla, incluyendo el invaluable nexo con instituciones extranjeras. Qué duda cabe, que el tener un mentor en etapas tempranas de la vida universitaria preocupado por el desarrollo integral y que abra las puertas al mundo puede resultar vital en la etapa de desarrollo de un joven. Sólo espero poder repetir, cuantas veces me sea posible, esta experiencia, ahora en calidad de mentor, con el máximo de jóvenes posibles. Quisiera aprovechar esta solemne oportunidad para presentarles el reciente libro de Humberto, "Futuros dueños del mundo"; un invaluable legado de un médico pediatra de excepción para todos quienes se relacionan o relacionarán con niños.

Mi estadía de casi cuatro años en Houston, Texas, me dio una perspectiva y apertura que podría homologar a un renacimiento intelectual en el área biomédica. Una vez más, la fortuna estuvo de mi lado al permitirme 
interactuar, día a día, en forma simultánea con dos grupos humanos de excepción. El primero, dirigido por mi mentor y hoy amigo, Dr. Larry Pickering, quien me enseñó a ser crítico en mi análisis, era implacable Larry en esto, y a escribir en inglés científico, una necesidad enorme en nuestro país para permitir que nuestros trabajos logren la visibilidad que muchas investigaciones se merecen, pero que tanto tardan o a veces no se logran por la falta de esta capacidad. Aprendí con rigor y tutoría dedicada. Poseía por cierto esa base del idioma adquirido de niño que ayudó en forma invaluable; pero una cosa es el idioma de niño y otra la escritura científica. Permítanme relatarles brevemente como aprendí: A la semana de inicio de mi Fellow, Larry me solicitó un escrito de cinco páginas máximo, sobre un pre-proyecto relativamente simple, para identificar diferentes tipos patogénicos de la bacteria Escherichia coli en muestras de deposiciones de niños de Jardines Infantiles; ¡mi primer proyecto propio! Mi sorpresa y depresión vino cuando me devolvió las cinco páginas con cientos de anotaciones, flechas, rayados, cambios (a mano, no había computador con Windows entonces) que terminó con un: "Buen trabajo, espero la segunda versión en tres días". Bueno, la segunda versión tuvo muchos aunque menos rayados, y así sucesivamente; ¡a la décima versión el manuscrito estaba listo! El próximo manuscrito tuvo siete revisiones, el tercero cuatro y de ahí en adelante sólo dos o tres, y al poco andar comencé a recibir de Larry, manuscritos de otros para revisión. Una lección de vida nuevamente: mentores con dedicación personalizada, dispuestos a dedicar mucho tiempo para que su pupilo crezca. En mi experiencia posterior esta dedicación a nuestros propios pupilos es la que da las mayores alegrías profesionales, especialmente cuando se logra visualizar que el terreno que uno abona permite que las nuevas generaciones crezcan más rápido y a mayor nivel del que uno logró. En Larry represento a un conjunto de investigadores académicos excepcionales de la Universidad de Texas, cada uno de los cuales me enseñó perlas de sus propias cosechas, que fueron enriqueciendo mi bagaje de conocimiento y mi formación como investigador, médico y persona. La posibilidad de salir a un período de formación, de al menos un año en un Centro extranjero de alto nivel, es fundamental para abrir la mente, a veces algo estrecha en su desarrollo en nuestro medio local. Esta posibilidad debe seguir siendo fuertemente incentivada en los Programas de impulso al desarrollo de Chile. Aprendí de Larry otra cualidad, propia de todos los líderes innatos con que me he relacionado, del cual me beneficié directamente: la de ser un facilitador de nexos virtuosos conducentes a una asociatividad prolífica. Larry me puso en contacto con David Matson, mi hoy cercano amigo y con Mary Estes, una mujer excepcional y prócer de la virología mundial - ambos de Baylor College- para adentrarme en el mundo de la biomedicina experimental; un magnífico complemento a la investigación en epidemiología clínica que se desarrollaba en mi grupo de la Universidad de Texas. Es en Baylor donde profundicé mi formación basada en la rigurosidad del método científico, donde sufrí las frustraciones del experimento fallido, experimenté el júbilo del primer paper aceptado, en fin, la pasión por la investigación biomédica experimental. ¿El factor común? Personas, destacadas todas, sencillas todas, dispuestas a aportar su conocimiento, ideas, tiempo, recursos, para apoyar el desarrollo de los jóvenes.

El sentido de pertenencia, el amor por el país, este concepto abstracto basado en vivencias de juventud, de afectos, de familia, de aromas, visiones, amores, así como una cierta esperanza de poder ser un aporte para un país CON FUTURO, me llevó a no titubear en mi decisión de regresar a Chile; el apoyo de Inés, por cierto, fue clave también en este aspecto pues se trató, como suele ser en estos momentos trascendentales, una decisión de familia, donde ella tuvo que renunciar a interesantes oportunidades propias. Muchas cartas envié para solicitar un espacio al cual volver, comprendía muy bien, que un espacio no era un derecho adquirido por haber tenido la fortuna de una formación en el exterior. ¡Porqué tendría que serlo!, si muchos de mis compañeros que se formaron en Chile tenían tanto o más derecho que yo por un lugar en un hospital o universidad. Recibí muchas respuestas cálidas que hoy agradezco, y una propuesta muy concreta que marcó mi vida futura. La Dra. Valeria Prado, me envió una carta a Estados Unidos, que en mi condición de "apasionado por el fútbol" me recordó la famosa frase (verdadera o no) de Carlos Dittborn "Porque no tenemos nada, queremos hacerlo todo". En la carta Valeria me expresaba: "Miguel es poco lo que tengo para ofrecerte, horas universitarias, un sueldo universitario, apoyo para tu instalación y muchas ganas de que te integres a nuestro grupo que quiere hacer mucho”. ¡Gracias Valeria, me diste todo $¡$ Personas con autoridad, que usen esta autoridad para abrir espacios a las nuevas generaciones, con calidez, con generosidad, sin temor, atreviéndose a correr algunos riesgos calculados, en otras palabras, líderes trascendentes, son claves para una sociedad que aspira a ser mejor. Por el contrario, autoridades con criterio rígido y restringido, donde prima el temor a la innovación y al desafío que conlleva la inserción de jóvenes talentos, que requieren cálculos excesivos para tomar decisiones, o que muestren arrogancia y/o poca generosidad en su rol de autoridad, son personas que atentan contra el desarrollo de la sociedad y debe evitarse por todos los medios que ejerzan posiciones donde el liderazgo que se requiere es otro. Quisiera señalar aquí, saltándome en los tiempos, que a través de estos 20 años en la Universidad de Chile, bastión de la educación pública de calidad y del fomento a la 
excelencia basada en la diversidad, donde me ha tocado ejercer diferentes posiciones y cargos, considero que me he encontrado, dentro y fuera de la Universidad, más con personas que ejercen "liderazgo" por sobre aquellas que ejercen "autoridad", sin perjuicio de lo cual, cada uno de esos escasos encuentros con una autoridad que hace prevalecer su jerarquía y posición por sobre la generosidad, receptividad y razonamiento lógico, ha sido un momento de tristeza y rebeldía que quisiera ayudar a desterrar de mi país.

Durante mi proceso de inserción a la División Oriente del Departamento de Microbiología y Micología de la Universidad de Chile (hoy un Programa unificado), vivencié la generosidad de mis compañeros, quienes aportaron con su propio tiempo para proteger mi dedicación a la investigación biomédica. La solidaridad del grupo la agradezco públicamente hoy, y la lección que aprendí de ellos es que se debe facilitar por todos los medios el proceso de inserción de los jóvenes a las universidades para que puedan emprender en forma productiva. No puedo dejar de reconocer hoy a mi fiel compañera del laboratorio, Nora Mamani y por su intermedio a todo el equipo del laboratorio y del Programa que me ha acompañado en estos años. Quizás uno de los pocos méritos personales que reconozco sin falsa modestia en este proceso, fue el de haber sido proactivo en ser un aporte para todos aquellos que pudieran beneficiarse con las habilidades, especialmente de investigación, escritura e idioma adquiridas durante mi etapa de formación. Con el transcurso de los años siento que esta actitud fue fundamental para abrir espacios y recibir afecto y apoyo de muchas personas para mis propios desarrollos futuros. Intento promover esta actitud entre las nuevas generaciones, que con agradable frecuencia, recibo en mi oficina para conversar sobre su futuro desarrollo.

Valeria tuvo la virtud además, al igual que mi mentor en Houston, de facilitar nexos con otros grupos, especialmente del área clínica; ella supo interpretar que además de la investigación, el contacto con la clínica era un anhelo vocacional en mi proceso de crecimiento profesional. Es así como me introdujo al maravilloso grupo humano de la Unidad de Infectología Pediátrica y a través de ellos, de otras unidades del Hospital Luis Calvo Mackenna. Durante 20 años he sido un invitado permanente del grupo. Con generosidad, flexibilidad, y afecto de estas personas de excepción, he podido complementar mis dos vocaciones, la investigación y la Infectología pediátrica. Se trata de grupos que han logrado conjugar de manera ejemplar para el país, el desarrollo de una atención clínica de alta calidad con la generación de nuevo conocimiento basado en proyectos de investigación concursables, que han derivado en publicaciones científicas de alto impacto. Son estos productos los que le han dado la autoridad entre sus pares para impulsar recomendaciones y guías terapéuticas que han tenido, a su vez, un impacto positivo relevante para la atención de pacientes a nivel nacional e internacional. A través de un activo fomento de la asociatividad con diferentes departamentos de la Universidad de Chile y la "Fundación de Amigos del Calvo Mackenna", el Hospital está desarrollando una iniciativa única y de gran proyección, un Centro de Investigación Pediátrica, liderado por la Dra. María Elena Santolaya con quien me unen años de profunda amistad. Un ejemplo a seguir que demuestra que con resolución, perseverancia y activa búsqueda de colaboraciones $y$ consensos, se puede desarrollar investigación de calidad, que resulta en la "generación de nuevo conocimiento", en el sistema público, que impacta en la mejor atención de nuestros pacientes $y$ en el prestigio internacional de nuestras instituciones. He visto con alegría como se respira en este grupo la generosidad, la apertura de criterio y ausencia de dogmatismos, el fomento a la renovación de excelencia incluyendo la entusiasta incorporación de la nueva camada de jóvenes médicos, bioquímicos, y otros profesionales con formación doctoral, es decir, nuevamente un liderazgo positivo pro-desarrollo, pro-país.

Quisiera resaltar, nuevamente, por tercera vez, la relevancia enorme de la asociatividad, colaboración, e integración como factor clave para alcanzar logros de mayor impacto; mi propia experiencia colaborativa con directivos, médicos, investigadores, y personal de diferentes hospitales, consultorios, colegios, salas cunas del país, y del exterior, ha sido un factor clave para el desarrollo y el éxito de los proyectos de envergadura que me ha tocado dirigir o participar en estos 20 años. Sin esta disposición generosa a colaborar, por un objetivo no pocas veces ajenos al diario quehacer de cada uno, los nuevos conocimientos con impacto internacional, generados desde Chile relacionados con la seguridad y eficacia de la vacuna rotavirus, con la caracterización del impacto epidemiológico de los calicivirus, así como del rol potencialmente dañino o protector de Helicobacter pylori en niños aparentemente asintomáticos, al igual que los significativos aportes en infecciones en neutropenia febril y pacientes inmunocomprometidos lideradas por mis colegas del Calvo Mackenna, no habrían sido posibles. Chile es un país pequeño y remoto que debe promover y facilitar la asociatividad de sus talentos y capacidades como medio fundamental para transformarse en una sociedad que aporta a la generación de nuevo conocimiento, y de potenciales nuevas tecnologías. Hoy estamos trabajando para desarrollar un Centro Internacional de Excelencia en Biomedicina que, de ser exitoso, asociará a la Universidad de Chile con la Pontificia Universidad Católica e Instituciones extranjeras; creo que éste es el camino a seguir para avanzar a paso firme hacia la sociedad del desarrollo. 
Las sociedades científicas han jugado un importante rol en favorecer sinergias entre profesionales de diferentes proveniencias, profesionales que en su totalidad comparten el anhelo de mantenerse actualizados en sus materias así como, en una mayoría, el de ser protagonistas de un siempre mejor sistema de salud y de propuestas de políticas públicas más robustas. La Sociedad Chilena de Infectología ha sido altamente relevante para el país gracias al aporte generoso de cientos de socios que no trepidan en entregar tiempo y esfuerzo para el mejor abordaje integral de las enfermedades infecciosas. En lo personal, ha sido un nicho para recibir y entregar conocimiento, dándome la posibilidad plena de devolver a la sociedad parte de lo mucho que yo he recibido. La acción mancomunada, colaborativa de personas provenientes de organismos públicos, privados, de las sociedades científicas, y las universidades, cada uno aportando su experiencia, con declaración de intereses trasparentes, favoreciendo las confianzas por sobre las suspicacias, me parece clave para alcanzar logros mayores en temas de salud que el país requiere. Quisiera en este aspecto, destacar la labor que ha desarrollado la destacada profesional y querida amiga, Dra. María Teresa Valenzuela en la Dirección del Instituto de Salud Pública; ella es una férrea defensora de esta asociatividad virtuosa, cuyos frutos hemos visto con gozo, en un Instituto hoy más sólido, con ideas y objetivos más claros, intensamente integrado con los diferentes actores de la sociedad, y con calidad técnica en ascenso progresivo, todas metas que anhelábamos casi con angustia en nuestras conversaciones de antaño.

"Mi vida es una vida hecha de todas las vidas", qué duda cabe que el factor común mas relevante para el buen desarrollo de una sociedad son las personas. Me congratulo de haber recibido y aquilatado perlas de cada uno de ustedes, alguna de las cuales he desarrollado en estas ya, excesivamente, largas palabras. No podría terminar sin agradecerles a todos, absolutamente a todos, por lo que me han entregado, por cierto a mis amigos y familia, muchos presentes hoy, y que no he mencionado uno por uno, porque vuestra entrega es en varios casos, más personal e íntima, más ligado al ámbito afectivo, del cual me excusé tempranamente en no profundizar. No puedo dejar de mencionar sin embargo, a Miguel, Sebastián y Rosario, mis tres maravillosos hijos, quienes nos han dado a Inés y a mí la alegría plena por tantas razones que sería muy largo describir. En esta etapa de mi vida recibo de cada uno consejos, estímulo, apoyo, consuelo, que hacen tanto más fácil y feliz el transcurso de mis días.

He disfrutado el proceso de reflexión durante estos meses, me ha permitido plasmar los conceptos que hoy he querido transmitir. Me vienen a la mente, para terminar, tres ideas fuerza que de una manera imperceptible adquirí, precozmente, y que me han acompañado en forma creciente a lo largo de los años: primero, que el sueño imposible que nos canta el Quijote y termina Dulcinea en el epílogo de esa hermosa obra musical que tanto me emocionó de niño, es posible, y es bello tener sueños; segundo, creo férreamente en que hay que intentar ser parte de las soluciones y no de los problemas, tratando de seguir el predicamento tan inspirador de uno de los demócratas norteamericanos más admirados, John Kennedy, especialmente, si la vida te da la oportunidad, de pensar primero cómo puede uno aportar a su comunidad, más que, en qué puede beneficiarse uno del sistema y finalmente, al enfrentar los desafíos, antes de decidir que algo no se puede hacer, pensar "qué se requiere para que ese algo sí ocurra".

Para quienes somos aficionados a correr, la meta es un logro, pero por lejos, más importante es el camino y quienes nos acompañan en ese camino. Muchas gracias por acompañarme en este importante día y en este camino; "Mi vida es una vida hecha de todas vuestras vidas, la vida de un privilegiado y de un agradecido".

Dr. Miguel O'Ryan G. 13 de septiembre de 2012 